\title{
A Proteção de Marcas do Segmento de Fitoterápicos
}

\author{
The Protection of Trademarks in the Phytotherapy Segment
}

\author{
Daniel Marques de Albuquerque ${ }^{1}$ \\ Sammy Aquino Pereira ${ }^{2}$ \\ ${ }^{1}$ Universidade Federal do Amazonas, Manaus, AM, Brasil \\ 2Instituto Nacional de Pesquisas da Amazônia, Manaus, AM, Brasil
}

\begin{abstract}
Resumo
Fitoterápicos são remédios reproduzidos a partir de partes vegetais ou plantas consideradas medicinais e que podem ser representadas pelas marcas, por meio de um ativo intangível. O objetivo deste trabalho é identificar o registro de marcas associadas a produtos fitoterápicos, com o intuito de avaliar se as empresas utilizam a estratégia de proteção da marca para validar seus produtos. A metodologia utilizada baseou-se na identificação da Classificação de Nice para fitoterápicos, o levantamento das marcas e empresas detentoras do registro, assim como a busca de informações na internet aberta sobre a comercialização das marcas identificadas. Como resultado, identificou-se que apenas cinco empresas estavam com suas marcas em vigor, mas apenas uma empresa utilizava a marca do produto fitoterápico. Portanto, pode-se demonstrar a baixa demanda pelo uso de ativo intangível no que se refere à comercialização de produtos fitoterápicos.
\end{abstract}

Palavras-chave: Propriedade Intelectual. Produtos Naturais. Amazônia.

\begin{abstract}
Herbal medicines are remedies reproduced from plant parts or plants considered medicinal and which can be represented by brands, through an intangible asset. The objective of this work was to identify the registration of brands associated with herbal products, aiming to assess whether companies use the brand protection strategy to validate their products. The methodology used was based on the identification of the Nice Classification for herbal medicines, the survey of trademarks and registered companies, as well as the search for information on the open internet on the marketing of the identified brands. As a result, it was identified that only five companies had their brands in force, but only one company used the herbal product brand. Therefore, one can demonstrate the low demand for the use of intangible assets with regard to the sale of herbal products.
\end{abstract}

Keywords: Intellectual Property. Natural Product. Amazon.

Área Tecnológica: Prospecção Tecnológica. Propriedade Industrial. Investimento. 


\section{Introdução}

O Brasil apresenta uma biodiversidade de espécies vegetais que apresentam diversos tipos de usos e que ainda permanecem desconhecidas. Ainda assim, aliada ao conhecimento tradicional e às pesquisas científicas básicas e aplicadas desenvolvidas ao longo do tempo, a sociedade tem acesso a um tipo de indústria em ascensão que é a de fitoterápicos (HASENCLEVER et al., 2017).

A fitoterapia, associada ou não ao tratamento convencional, traz inúmeros benefícios ao paciente, somado a um menor custo financeiro. Essa prática de uso de fitoterápicos é muito antiga, já que as plantas eram usadas na sua forma natural, na preparação de chás, unguentos, emplastos e outros, pelos povos tradicionais e pela população brasileira em geral, nas mais diversas situações de saúde (BUENO; MARTINEZ; BUENO, 2016).

Os fitoterápicos apresentam uma parcela significativa no mercado de medicamentos, movimentando globalmente U\$ 44 bilhões por ano. No Brasil, estima-se que esse mercado gira em torno de $\mathrm{R} \$ 700$ milhões a $\mathrm{R} \$ 1$ bilhão por ano, tornando-se um nicho de mercado que vem ganhando notoriedade, pela associação desse tipo tratamento ao de "vida saudável", em que o uso de produtos naturais e fitoterápicos representam uma alternativa terapêutica menos agressiva ao organismo. A principal característica desse nicho é que ele apresenta como base o uso de plantas, diferentemente dos medicamentos que utilizam substâncias processadas.

Essa identidade dada aos fitoterápicos divulgada na mídia está associada às marcas que as empresas utilizam para a divulgação de seus produtos. A marca, por se caracterizar de identidade visual, acaba ganhando legitimidade e transformando um negócio, pois agrega ao produto real um conjunto de valores e de referências que contribuem para diferenciá-lo de outros, de acordo com o setor econômico.

As marcas são "[...] todos os sinais distintivos, visualmente perceptíveis, que identificam e distinguem produtos e serviços, bem como certificam a conformidade dos mesmos com determinadas normas ou especificações técnicas [...]", garantindo o direito de uso exclusivo no território nacional em seu ramo de atividade econômica (INPI, 2020a).

O registro de marcas no Brasil ou em outros países é importante por ser objeto imaterial valioso, se traduzindo na identidade do negócio perante o mercado e seu público. Dessa forma, o objetivo deste trabalho é identificar o uso de marcas associadas a produtos fitoterápicos, por meio da identificação das empresas que fazem uso desse ativo de propriedade industrial e se esses produtos estão sendo comercializados, de modo que possa entender se a estratégia de proteção da marca está sendo utilizada na Amazônia.

\section{Referencial Teórico}

O referencial teórico exposto nesta pesquisa apresenta uma breve explanação sobre fitoterápicos e marcas, de forma a elucidar a importância dos remédios fitoterápicos e do uso de marcas para identificação, bem como a proteção de ativos de uma empresa. 


\subsection{Fitoterápicos}

A palavra Fitoterapia deriva da junção de dois termos em grego, "Phyton" que significa vegetal e "Therapeia" cujo significado é terapia, originando o termo "terapia utilizando plantas". A Organização Mundial da Saúde (OMS) define fitoterápicos como um termo amplo que "[...] inclui ervas, materiais à base de plantas, preparações à base de plantas e produtos acabados à base de ervas" (BUENO; MARTINEZ; BUENO, 2016).

A Resolução da Diretoria Colegiada (RDC) n. 26/2014 (ANVISA, 2014) define fitoterápico como um "[...] produto obtido de matéria-prima ativa vegetal, com finalidade profilática, curativa ou paliativa, incluindo medicamento fitoterápico e produto tradicional fitoterápico". A Fitoterapia, hoje em dia, se fundamenta em várias áreas relacionadas à saúde, como a fisiologia, a química e a bioquímica, e está sujeita à regulamentação em farmacovigilância (BRASIL, 2006).

O uso de plantas medicinais para cura e tratamento de doenças acompanha as sociedades humanas desde a sua existência e, no Brasil, não é diferente, pois esse conhecimento está relacionado intimamente às populações tradicionais, as quais transmitem essa experiência com o "tipo de planta, preparo e aplicação", ao longo de gerações de forma oral, o que, por sua vez, acaba se perdendo com as mudanças de vida e do ambiente.

A maioria da população acredita que o uso de plantas medicinais evita mais riscos à saúde, no entanto, muitas plantas são tóxicas e necessitam de manuseio e de preparo correto para o melhor aproveitamento dos seus princípios ativos. Dessa forma, algumas medidas governamentais foram adotadas para estabelecer estratégias de acesso aos fitoterápicos, mas também promover o desenvolvimento produtivo e inovativo nessa indústria, a saber: a Política Nacional de Plantas Medicinais e Fitoterápicos (Decreto n. 5.813/2016), a Política Nacional de Ciência, Tecnologia e Inovação em Saúde (2008), a Relação Nacional de Plantas Medicinais de Interesse ao SUS-RENISUS (2009), a RDC n. 60 (2011); a Publicação da Rename (2012), a RDC n. 26/2014 e a Lei n. 13.123/2015 (MINISTÉRIO DA SAÚDE, 2021).

Além das medidas tomadas diretamente pelo Ministério da Saúde, há de se ressaltar o papel da Anvisa no processo de revisão e incorporação de novas informações e requisitos de qualidade da Farmacopeia Brasileira, entre estes, o Formulário de Fitoterápicos da Farmacopeia Brasileira (ANVISA, 2021), que hoje contém 85 monografias, relacionadas a 85 espécies, com o intuito de apoiar o desenvolvimento e a produção de produtos fitoterápicos com qualidade para a população brasileira.

Ainda, na Anvisa, há o registro de 1.553 medicamentos fitoterápicos, dos quais são válidos 511 produtos, devido à normativa de duração de dez anos, a partir da data de publicação do registro no Diário Oficial da União (DOU), em todo território nacional.

Costa et al. (2013) observaram que grande parte dos insumos farmacêuticos vegetais é proveniente de outros países, apresentando, assim, um déficit de produção e composição de fitoterápicos para a escala industrial. Essa situação representa uma oportunidade para o Brasil, considerando nossa dotação natural advinda da biodiversidade, mas também pelo conhecimento tradicional e científico acumulado no país. 
No entanto, Costa et al. (2013) sugerem ainda que a dependência externa a esses insumos sinaliza a fragilidade da base produtiva e a baixa taxa de inovação da indústria nacional. A literatura científica traz algumas causas que conduzem a essa situação:

a) O cultivo de plantas medicinais que está relacionado à agricultura familiar, na qual por muitas vezes não há infraestrutura adequada de cultivo e processamento das plantas (TERRA JUNIOR; MALDONADO; ARNOBIO, 2015).

b) Os produtores rurais possuem baixa assistência técnica, baixa produtividade, pouca infraestrutura e linhas de crédito para esse tipo de produção, além das condições de escoamento da produção, que contribuem para uma atividade pouco atrativa e economicamente pouco viável (RICARDO, 2009).

c) A falta de desenvolvimento de ações integradas, visando à agregação de valor, faz com que a produção seja quase toda vendida in natura para a etapa seguinte da cadeia de valor (BUENO; MARTINEZ; BUENO, 2016).

d) A falta de padronização da matéria-prima e sua qualidade. "Existem muitos produtos com nomes iguais, mas de espécies diferentes. Composições químicas diferentes possuem efeitos farmacológicos distintos" (TERRA JUNIOR; MALDONADO; ARNOBIO, 2015).

e) A falta de um marco regulatório capaz de harmonizar os interesses de uma extensa cadeia produtiva, desde o cultivo das plantas, o manejo sustentável, a Pesquisa e o Desenvolvimento (P\&D), a produção, a distribuição de fitoterápicos, os pedidos de patentes por empresas brasileiras (HASENCLEVER, 2009; HASENCLEVER et al., 2017).

f) A indústria brasileira de fitoterápicos é constituída por um grande número de empresas, de capital estrangeiro e nacional, mais voltadas para a produção de medicamentos acabados do que de insumos (TORRES, 2013).

Nessa perspectiva, a indústria brasileira de fitoterápicos tem tido dificuldade em se adequar aos padrões de produção e qualidade, devido não somente às próprias regulamentações e normatizações nacionais, mas também pela dificuldade ao acesso a insumos ou matérias-primas de qualidade para produção em escala industrial, assim como sua disponibilização no mercado, de forma clara para o consumidor final.

\subsection{Marcas}

O uso de marcas advém da Idade Média, em que as corporações de ofício e de mercadores as utilizavam para controlar a quantidade e a qualidade da produção. Na época das grandes navegações e com a intensificação do comércio, adquiriram maior importância para a identificação da origem e da qualidade dos bens. Com o avanço da Revolução Industrial, houve as primeiras iniciativas de proteção e registro de marcas. Na segunda metade do século XX, com a substituição dos produtos artesanais por industriais e o avanço de novos modelos de mercado, inclusive com maior comunicação, as marcas ganharam mais força e importância e passaram a constituir-se em importante expressão da vida moderna (PINHO, 1996). 
A marca existe para comunicar o que a organização dispõe de produto ou serviço para o público de interesse, constituindo elementos, como o nome, o símbolo ou o logotipo, para definir esse objetivo. Para a empresa dispor dessa marca no mercado, são criados os elementos comunicacionais, como domínio na internet, slogans, jingles, embalagens e demais peças publicitárias, de promoção e de patrocínios, que agregam ainda benefícios funcionais, expressivos, emocionais e sensoriais, de uma proposta, de uma imagem e da qualidade de seu relacionamento com o futuro público (AAKER, 1991; BATEY, 2010).

Utilizando-se de mídias digitais, as marcas diversificaram seus suportes de contato, relação e atuação com o consumidor em diversas áreas, como políticas, esportivas e culturais. Por exemplo, na política, em 2018, a empresa Ben \& Jerry's criou sorvete Pecan Resist que, de acordo com a marca, tem como objetivo "[...] um movimento para desafiar a injustiça e celebrar os que lutam para criar uma nação mais justa e igualitária para todos”.

Na área esportiva, a cidade do Rio de Janeiro, em 2016, sediou os Jogos Olímpicos e Paralímpicos, e as marcas dos eventos trazem uma série de símbolos que são imediatamente reconhecidos e que criam a identidade dos Jogos, como o Aro Olímpico, que "[...] interligados trazem as cores azul, preta, verde, amarela e vermelha, que representam a união dos cinco continentes".

$\mathrm{Na}$ área cultural, existe a marca Disney que se destaca no mundo do entretenimento, como a representação do local onde "a magia está". Em 2020, a Interbrand publicou o ranking Best Global Brands, no qual a empresa está entre as 10 marcas mais valiosas do mundo, atrás de empresas como Apple, Amazon e Microsoft (Figura 1).

Figura 1 - Best Global Brands 2020

\begin{tabular}{|c|c|c|c|c|c|}
\hline \multirow{3}{*}{$\begin{array}{l}01 \\
\text { maçã } \\
+33 \% \\
\$ 322999 \text { milhöes }\end{array}$} & $\begin{array}{l}02 \\
\text { Amazonas }\end{array}$ & $\begin{array}{l}03 \\
\text { Microsoft }\end{array}$ & $\begin{array}{l}04 \\
\text { Google }\end{array}$ & $\begin{array}{l}05 \\
\text { Samsung }\end{array}$ & $\begin{array}{l}06 \\
\text { Coca Cola }\end{array}$ \\
\hline & $\begin{array}{l}+60 \% \\
\$ 200.667 \mathrm{~m}\end{array}$ & $\begin{array}{l}+53 \% \\
\$ 166.001 \mathrm{~m}\end{array}$ & $\begin{array}{l}-1 \% \\
\$ 165,444 \mathrm{~m}\end{array}$ & $\begin{array}{l}+2 \% \\
\$ 62.289 \mathrm{~m}\end{array}$ & $\begin{array}{l}-10 \% \\
\$ 56.894 m\end{array}$ \\
\hline & amazon & Microsoft & Google & SAMSUNG & Confola \\
\hline \multirow{3}{*}{$\begin{array}{l}07 \\
\text { Toyota } \\
\$ 51.595 \mathrm{~m}\end{array}$} & $\begin{array}{l}08 \\
\text { Mercedes- } \\
\text { Benz }\end{array}$ & McDonald's & 10 & BMW & $\begin{array}{l}12 \\
\text { Intel }\end{array}$ \\
\hline & $\begin{array}{l}-3 \% \\
\$ 49.268 \mathrm{~m}\end{array}$ & $\$ 42.816 \mathrm{~m}$ & $\$ 40,773 \mathrm{~m}$ & $\$ 39.756 \mathrm{~m}$ & $\$ 36.971 \mathrm{~m}$ \\
\hline & 6 & & DiSNEP & $(4)$ & \\
\hline
\end{tabular}

Fonte: Interbrand (2020)

As marcas mantêm, além do papel de agregar a sua simbologia, os valores, os propósitos e os estilos de vida a um produto ou serviço, também apresentam a função de identificar, de referenciar procedência e qualidade, nos papéis de marca coletiva, de certificação e de alto renome, respectivamente (INPI, 2020a).

No Brasil, as marcas estão regulamentadas pela Lei n 9.279/96, que regula os direitos e obrigações relativos à Propriedade Industrial. $\mathrm{O}$ pedido de proteção de marca é realizado no Instituto Nacional da Propriedade Industrial (INPI) e possui validade de 10 (dez) anos, contados da data da concessão, sendo prorrogáveis por períodos iguais e sucessivos. 
Em 2019, o país aderiu ao Protocolo de Madri, no qual o requerente de registro de marca pode optar em requerer a proteção, ao mesmo tempo, em diversos países com um único processo, em um único idioma. Tal Protocolo permite ao usuário uma maior previsibilidade do tempo da resposta, com uma única data de prorrogação, com pagamento em uma única moeda e reduzindo custos (INPIc).

Com base no Relatório de Atividades do INPI (2018), houve uma variação no número de registros de marcas, de 75.531 pedidos em 1999 para 176.063 em 2018, sendo um aumento de $133 \%$ do número de pedidos de proteção relativos a residentes do país ao ano. O Ministério da Ciência, Tecnologia e Inovações (MCTI), por meio do Formulário para Informações sobre a Política de Propriedade Intelectual das Instituições Científicas, Tecnológicas e de Inovação do Brasil (FORMICT), realiza anualmente um levantamento junto às Instituições Científicas, Tecnológicas e de Inovação (ICT) do País.

O Formict (2019), ano base 2018, foi preenchido por 305 instituições, das quais 209 apresentaram-se como instituições públicas e 96 como instituições privadas. Esse relatório busca obter informações sobre a gestão das ICTs e dos Núcleos de Inovação Tecnológica (NIT). No item de Proteções de Propriedade Intelectual, foi possível observar o quantitativo de ICTs que protegem suas marcas, 173 públicas e 46 privadas, valores muito baixos se comparados ao número de registros no INPI.

No que se relaciona ao tipo de proteção por setor econômico, no registro de marcas para produtos e serviços, se destacam os setores de "Atividades profissionais, científicas e técnicas" (77 registros) e "Agricultura, pecuária, produção florestal, pesca e aquicultura" (40 registros).

Esses resultados demonstram que registrar marcas não é apenas possuir um nome e um logotipo, mas transformá-la em uma representação e significado para os consumidores para que alcancem um valor de mercado. Em outras palavras, a experiência de uso de uma marca deve ser a mais próxima possível da estratégia da marca, o branding. A palavra branding costuma ser traduzida para a língua portuguesa pelas expressões "construção da marca e gestão da marca" ou "um conjunto de atividades que visa a otimizar a gestão das marcas de uma organização como diferencial competitivo" (KELLER; MACHADO, 2006; FERREIRA, 2018).

As marcas possuem uma principal vantagem como ativo, a agregação de valor aos produtos ou serviços prestados, reconhecidos pelo consumidor; os quais podem ser licenciados ou franquiados, incrementando a receita do negócio. As marcas ainda possuem valor financeiro, podendo ser vendidas e até mesmo utilizadas como argumento de venda, pois o mercado consumidor sente maior segurança em adquirir produtos ou contratar serviços de marcas conhecidas (MEDEIROS FILHO; RUSSO, 2015; TAVARES, 2016; SEBRAE, 2020).

\section{Metodologia}

O presente artigo se enquadra no termo quanti-qualitativo, ou seja, aborda características dos dois métodos simultaneamente. Com relação ao objetivo, pode-se classificar como descritiva por "[...] descrever as características de uma população, um fenômeno ou experiência para o estudo realizado" (MAZUCATO et al., 2018, p. 60). Considerando a afirmação de que 
"[...] a pesquisa documental tem como fonte documentos no sentido amplo, ou seja, não só de documentos impressos, mas sobretudo de outros tipos de documentos, tais como jornais, fotos, filmes, gravações, documentos legais" (SEVERINO, 2017, p. 122). Com relação às técnicas utilizadas, pode-se classificá-la como pesquisa documental, pois o presente artigo teve como fonte de dados principal a base de marcas do Instituto Nacional da Propriedade Industrial (INPI).

Inicialmente, foi identificado na Classificação Internacional de Produtos e Serviços de Nice (NCL (11) 2020) qual a classificação para produtos fitoterápicos, que resultou na Classificação "5", que trata de "Preparações fitoterápicas para fins medicinais", com número de base 050455.

A Classificação de Nice possui uma lista de 45 classes com informações sobre os diversos tipos de produtos e serviços pertencentes a cada classe. Os produtos são listados nas classes 1 a 34, e serviços listados nas classes 35 a 45 (INPI, 2020b).

A partir da Classificação identificada, buscou-se na base de marcas do Instituto Nacional da Propriedade Industrial (INPI) as marcas na Classificação 5. No entanto, para realizar a busca, foi necessário identificar termos para correlacionar com a Classificação, a fim de recuperar as marcas de produtos de fitoterápicos. Assim, foram utilizadas três estratégias descritas na Tabela 1.

Tabela 1 - Estratégias de busca

\begin{tabular}{cc} 
EstratÉGia & REsultados \\
fito + Classificação 5 & 463 \\
amazonia + Classificação 5 & 85 \\
amazon + Classificação 5 & 296 \\
\hline
\end{tabular}

Fonte: Elaborada pelos autores deste artigo (2020)

Com os dados recuperados, estes foram filtrados para retirar as revocações e resultados que não coincidiam com a pesquisa. Em seguida, as informações foram tabuladas em planilha do Excel e foram identificadas: a quantidade de marcas por situação no INPI, subclassificações de Nice mais ocorrentes e número de marcas por tipo. Das empresas com marcas em situação ATIVA, foram identificados: os produtos, para que servem, se utilizam espécies amazônicas na composição, e quais as empresas realmente atuavam com fitoterápicos.

\section{Resultados e Discussão}

O resultado final das buscas gerou um total de 57 marcas dentro da Classificação 5. Primeiramente foi avaliada a situação (status) das marcas junto ao INPI, sendo identificada que a maior parte estão em domínio público, quer seja por extinção ou arquivamento (Gráfico 1).

A extinção de marcas se dá por três formas: pelo fim de sua vigência, pela caducidade ou pela inobservância do artigo 217 da Lei da Propriedade Industrial (INPI, 2020a). O artigo 217 determina que a "[...] pessoa domiciliada no exterior deverá constituir e manter procurador devidamente qualificado e domiciliado no País, com poderes para representá-la administrativa e judicialmente, inclusive para receber citações" (BRASIL, 1996). 
Gráfico 1 - Quantidade de marcas por situação no INPI

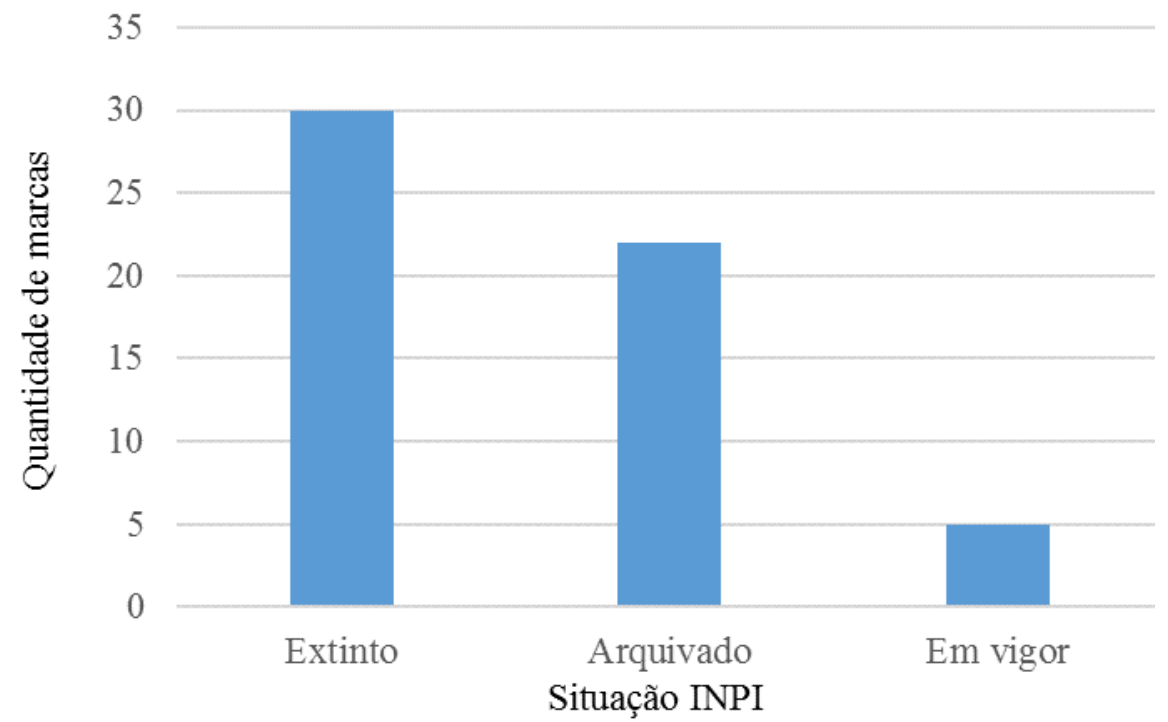

Fonte: Elaborado pelos autores deste artigo (2020)

De acordo com o INPI (2020a), o arquivamento pode ocorrer por falta de: procuração, documentos relativos à marca de certificação, documentos relativos à marca coletiva, resposta à exigência de mérito e por falta de pagamento das retribuições relativas à concessão do registro.

Castaldi (2018) destaca que pesquisas usando marcas registradas ainda são bastante limitadas e que estão em desacordo com a premissa de que são os ativos de propriedade industrial mais amplamente usada em diferentes setores econômicos e tamanhos de empresas. Em sua revisão de literatura, ela apresenta o papel das marcas como complementar às patentes na visão das empresas, no que se refere aos setores, em termos de intensidade, motivos e práticas.

A autora diz ainda que é essencial compreender o registro da marca por dois motivos: para interpretar os padrões de registros e fornecer insights sobre as possibilidades de uso de dados de marca registrada para medir variáveis econômicas específicas, como diversificação e capacidade de inovação (CASTALDI, 2018).

Hasenclever et al. (2017), em estudo sobre produtos fitoterápicos, compararam uma lista de registros de produtos de 2009 com a de 2015 e observaram uma redução drástica de $72 \%$ no número de registros. Ainda "[...] apresentaram uma lista de empresas detentoras desses registros, em 2009, que continha 166 empresas com distribuição, no território nacional, bastante desigual" (HASENCLEVER et al., 2017, p. 2.561).

No que se refere às marcas em vigor, forma obtidos apenas cinco resultados, os quais serão melhor analisados a seguir. Quanto à temporalidade dos registros de marca referente ao objeto de busca, observa-se que a maior parte é de registro antigo (Gráfico 2), que condiz com a situação identificada no Gráfico 1 quanto à extinção dos registros. São registros antigos de marcas e que as últimas do ano de 1999 referem-se às marcas que estão em vigor, ou seja, apresentam três prorrogações de prazo.

Medeiros Filho e Russo (2015) identificaram em estudo sobre a gestão de registro de marcas em empresas sergipanas que, numa amostra de 761 empresas pesquisadas, apenas 68 destas efetuaram registro de marcas, eles verificaram, ainda, a existência de empresas que pediram registro de marca no mesmo ano de sua abertura, assim como empresas que demoraram até 44 anos para realizá-lo, demonstrando uma alta média de tempo para realizarem o pedido de registro. 
Gráfico 2 - Número de marca por registro de ano

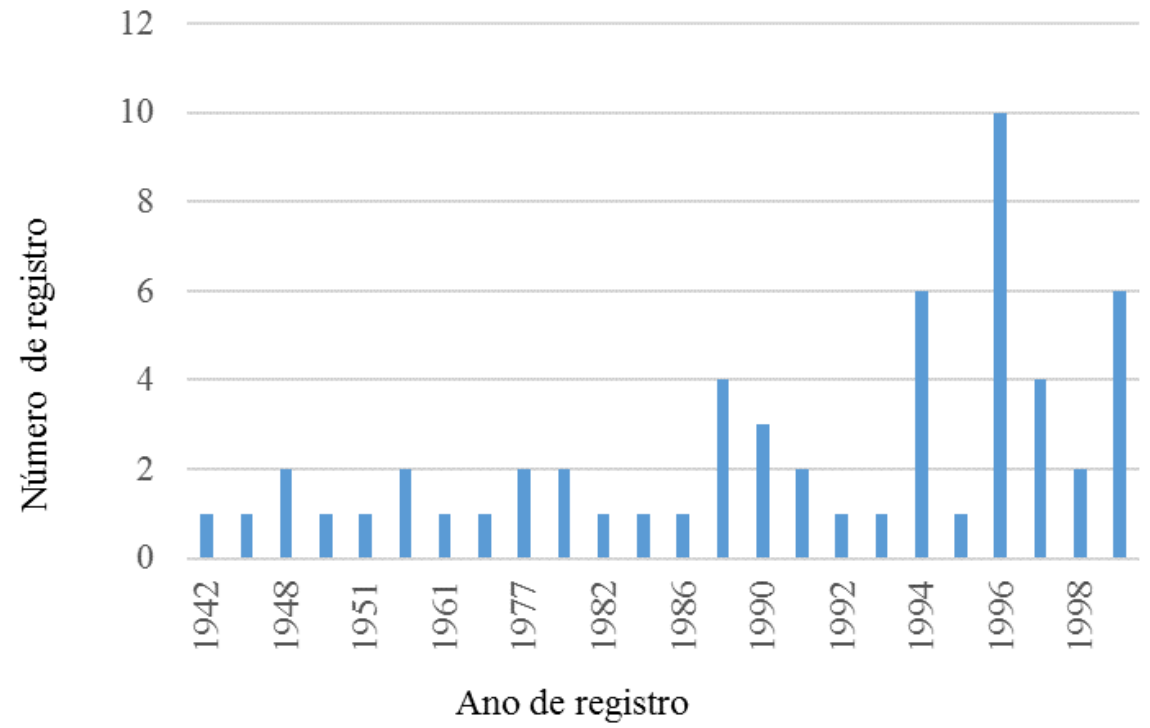

Fonte: Elaborado pelos autores deste artigo (2020)

Há ainda que se destacar que, de acordo com o Relatório do INPI, os estados brasileiros que mais solicitaram registro de marcas em 2019 foram São Paulo (37,3\% de registros), Minas Gerais $(10,1 \%)$, Rio de Janeiro $(8,6 \%)$ e Paraná $(8,1 \%)$, os quais apresentaram crescimento em relação aos pedidos do ano anterior. Nenhum Estado incluído na Amazônia se destacou em registro de marcas, o que corrobora o baixo resultado de registros identificados.

No mesmo Relatório, na análise sobre a Classificação de Nice, destacou-se entre os residentes, no primeiro lugar, a classe 35 (21,9\%), que corresponde às marcas para publicidade e gestão de negócios; a classe 41 (12,8\%,), relativa à educação, entretenimento, atividades desportivas e culturais; e a classe $25(6,1 \%)$, que se refere a vestuário, calçados e à chapelaria.

Por outro lado, entre os não residentes, as classes com o maior número de registros foram: a classe 9 (12,5\%), relativa a instrumentos científicos e eletrônicos; a classe 5 (8,0\%) de produtos farmacêuticos; e a classe 35 (7,3\%). Observa-se, assim, o baixo uso no país do registro de marcas, no que se refere à classe 5 , buscada por fitoterápicos, enquanto empresas de outros países utilizam desse ativo de forma mais significativa.

Na Tabela 2, estão apresentadas as empresas com marcas em vigor. Consta a descrição dessas empresas e de suas marcas. A empresa DERMAVITA INDÚSTRIA E COMÉRCIO DE PRODUTOS FARMACÊUTICOS EIRELI - EPP, com matriz em Santa Catarina, possui atuação principalmente na: Fabricação de produtos farmoquímicos, Comércio atacadista de cosméticos e produtos de perfumaria, Comércio atacadista de produtos de higiene pessoal e Comércio varejista de cosméticos, produtos de perfumaria e de higiene pessoal (CNPJ, 2020). Em 1992, a Dermavita iniciou suas atividades com uma farmácia de manipulação. Em 2000, foi criada a divisão industrial para a produção cosmecêutica e de cosméticos. A marca ESSÊNCIA DA AMAZÔNIA protegida pela empresa não foi localizada em seu site.

No entanto, ao realizar a busca na internet aberta, foi recuperada a identificação de uma empresa na cidade de Manaus (AM) que comercializa produtos para a fabricação de cosméticos e materiais de limpeza, com o nome da referida MARCA. 
Tabela 2 - Lista das empresas em vigor e produtos

\begin{tabular}{|c|c|c|c|c|}
\hline Titular & $\begin{array}{l}\text { Quantidade } \\
\text { de marcas }\end{array}$ & $\begin{array}{c}\text { Tipo de } \\
\text { Apresentação }\end{array}$ & Marca & Imagem \\
\hline $\begin{array}{c}\text { DERMAVITA INDÚSTRIA E } \\
\text { COMÉRCIO DE PRODUTOS } \\
\text { FARMACÊUTICOS } \\
\text { EIRELI - EPP }\end{array}$ & 2 & Mista & $\begin{array}{c}\text { Essência } \\
\text { da } \\
\text { Amazônia }\end{array}$ & Amazônio \\
\hline $\begin{array}{l}\text { FITOBEL INDÚSTRIAS } \\
\text { REUNIDAS LTDA - ME }\end{array}$ & 1 & Nominativa & Fitomelito & \\
\hline $\begin{array}{l}\text { ZYDUS NIKKHO } \\
\text { FARMACÊUTICA LTDA }\end{array}$ & 1 & Nominativa & Fitosoma & \\
\hline HYPERA S.A. & 1 & Nominativa & Fitolax & \\
\hline
\end{tabular}

Fonte: Elaborada pelos autores deste artigo (2020)

A empresa FITOBEL INDÚSTRIAS REUNIDAS LTDA - ME, com o mesmo nome fantasia, com matriz no Ceará e Pará, atua principalmente no: Comércio atacadista especializado em outros produtos alimentícios não especificados anteriormente (CNPJ, 2020). A empresa é um entreposto de mel e cera de abelha, cadastrada junto ao Ministério da Agricultura do Estado do Pará, autorizada a fabricar produtos alimentícios à base de mel e seus derivados.

Na Figura 2, é possível observar os produtos da empresa, inclusive da MARCA FITOMELITO, protegida no INPI. O produto da referida marca encontra-se em xarope, spray e sachê, possui em sua composição um composto de mel com própolis e ervas naturais (alho e eucalipto) e enriquecido com ervas da Amazônia (copaíba), indicado na prevenção de diversas doenças e na lubrificação do trato respiratório (EXTRAFARMA, 2020).

Figura 2 - Produtos da empresa Fitobel

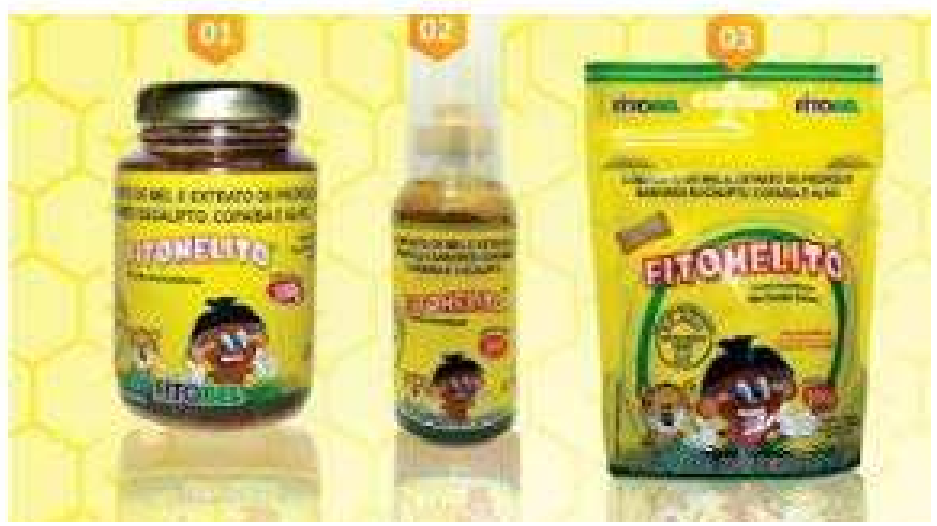

Fonte: Fitobel (2020a)

Dessa forma, a empresa apresenta um produto com uma marca, registrada na classe destinada a fitoterápicos, que utiliza plantas listadas (alho e eucalipto) no Formulário de Fitoterápicos. A copaíba ainda não consta no formulário por não ter uma monografia provada relacionada à sua espécie. Apesar de apresentar essa configuração, nem o produto e nem a empresa foram identificados na lista de medicamentos fitoterápicos da Anvisa, no que se relaciona a fitoterápicos.

A empresa ZYDUS NIKKHO FARMACÊUTICA LTDA é sócia da empresa QUÍMICA FARMACÊUTICA NIKKHO DO BRASIL LTDA. Esta última atua principalmente na: Fabricação de 
medicamentos alopáticos para uso humano, Fabricação de medicamentos fitoterápicos para uso humano, Comércio varejista de produtos farmacêuticos, sem manipulação de fórmulas e Comércio varejista de cosméticos, produtos de perfumaria e de higiene pessoal (CNPJ, 2020). Atua com matriz no Estado do Rio de Janeiro. A ZYDUS é uma das cinco maiores empresas da Índia e estão presentes em quatro continentes com 35 fábricas ao redor do mundo, sendo uma no Brasil, há 60 anos, e oito centros de pesquisas e desenvolvimento. A empresa atua "Na busca por comunidades cada vez mais saudáveis, colocando à disposição de médicos e pacientes medicamentos inovadores que seguem rígidos padrões internacionais de qualidade e segurança”.

Essa empresa apresentou em seu extenso portfólio dois produtos fitoterápicos com registro na Anvisa. No entanto, não foi localizado produto vinculado à marca "FITOSOMA". Na busca na internet aberta, não foi recuperada nenhuma informação correlacionando a marca Fitosoma, mas sim sobre um ingrediente para geração de outros produtos para a saúde.

A empresa HYPERA S.A., nome fantasia HYPERA PHARMA, é uma empresa com matriz em São Paulo e com filial em São Paulo, Goiás, Minas Gerais e Rio de Janeiro. Iniciou seus trabalhos em 1999, com atividades principalmente na: Fabricação de medicamentos alopáticos para uso humano, Comércio atacadista de cosméticos e produtos de perfumaria, Comércio atacadista de produtos de higiene pessoal e Comércio atacadista de instrumentos e materiais para uso médico, cirúrgico, hospitalar e de laboratórios (CNPJ, 2020).

Essa empresa apresentou em seu extenso portfólio oito produtos com princípio ativos de plantas. No entanto, não foi localizado nem em seu site e nem na Anvisa produto vinculado à marca "FITOLAX". Na busca na internet aberta, foram identificados diversos produtos com a marca Fitolax, mas não relacionados à empresa, classificados como laxantes, para obstipação intestinal, como pode ser observado pelo produto exposto na Figura 3.

Figura 3 - Produto com a marca Fitolax

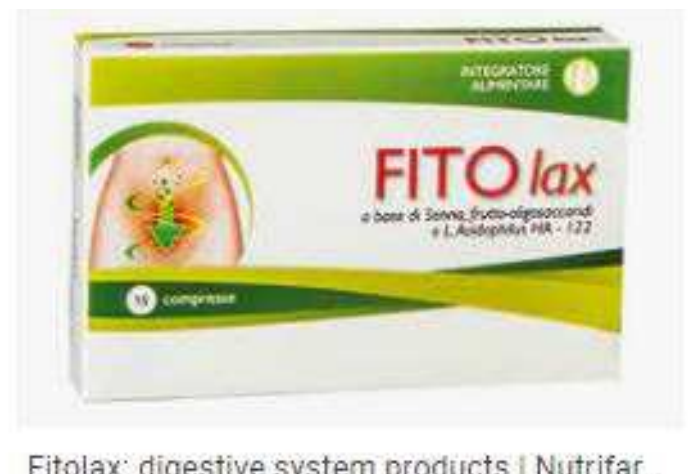

Fonte: Nutrifarma (2020)

Na Região Norte, há muitas plantas medicinais e produtos formulados a partir dessas plantas que são comercializados em feiras, mas que não apresentam registro junto à Anvisa $e$ muito menos marcas registradas.

Hasenclever et al. (2017, p. 2.560) destacaram que, pelo lado da demanda de fitoterápicos, os maiores desafios são: "[...] a definição de elementos suficientes de caracterização dos produtos (formas de apresentação, dosagem, etc.) publicados na Relação Nacional de Plantas Medicinais e de Fitoterápicos; e a compra do SUS destes medicamentos". 
Os autores se referem à necessidade da compilação de informações sobre uso de partes das plantas, dosagens, formulações, indicações e preparos utilizados no conhecimento básico da população, bem como da academia de forma a compilar em uma monografia a ser validada para inserção na Relação Nacional de Plantas Medicinais e de Fitoterápicos e no SUS.

Pereira (2018) detectou em seu estudo que existe uma dificuldade para o registro de marcas e isso leva ao desestímulo ao seu uso ou abandono do processo de registro, ainda nos trâmites iniciais; assim como apresentou que existe pouca clareza sobre o funcionamento do sistema de registro de marcas para o empresariado que mais utiliza esse processo

Outro grande gargalo no que se relaciona à Marca x Nome comercial da empresa, cabendo uma maior disseminação das principais diferenças entre o registro de uma marca e um nome comercial, que está, principalmente, na proteção. O registro da marca é que dá a proteção de uso do nome sobre produtos e serviços nacionalmente, enquanto o nome comercial é local e ligado à própria existência da empresa. Há ainda, o logotipo ou símbolo, bastante utilizado no comércio, que também difere da proteção por marca, que é muito mais ampla do que somente a informação visual de um produto ou serviço.

Um fator importante a se destacar é a proteção de medicamentos, pois, muitas vezes, o empresário enxerga como melhor estratégia de proteção do seu produto o pedido de patente ao invés do registro de marca. França e Vasconcelos (2018), ao acompanharem os depósitos de pedidos de patentes de fitoterápicos publicados no INPI entre 1995-2017, verificaram que dos 876 pedidos de patentes brasileiros, 377 foram de inventores independentes, 147 de empresase 257 de universidades, entre outros. No entanto, dos 876 pedidos de patente analisados, 59,2\% encontravam-se indeferidos ou arquivados, e apenas 12 patentes concedidas (1,3\% do total depositado), o que levou eles a concluírem que os depositantes brasileiros não estão conseguindo transformar suas pesquisas sobre fitoterápicos em invenções protegidas pelo sistema de patentes.

Portanto, observou-se neste levantamento um número baixo de produtos fitoterápicos com marcas registradas e certa dificuldade de correlacionar a marca aos produtos, além do que se pôde inferir, nota-se que há uma grande necessidade de capacitação empresarial no que se refere à proteção da propriedade industrial e seus tipos.

\section{Considerações Finais}

A pesquisa permitiu identificar a pouca utilização do uso de marcas como estratégia de negócios na Amazônia. Os resultados mostraram que a maior parte dos registros estão em domínio público há bastante tempo e que as empresas com registro ativo da marca não as utilizam de forma efetiva. Observou-se apenas uma empresa que demonstrou que realmente faz uso desse ativo como negócio. E outra que, apesar da proteção estar em vigor, não faz uso da marca, a qual é bastante utilizada no mercado, provavelmente a empresa licencia sua marca para outras, tendo em vista que pela internet é possível mensurar vários estabelecimentos utilizando tal marca.

Este trabalho contribuiu para demonstrar que as empresas necessitam compreender o potencial de uso de marca, identificar as potencialidades e deficiências nas suas marcas de produtos, de forma a alcançar seu posicionamento no mercado de fitoterápicos, uma vez que marcas bem geridas constituem-se em vantagem competitiva, lucratividade e longevidade para o negócio. 


\section{Perspectivas Futuras}

Ante os resultados obtidos, vislumbra-se uma série de oportunidades para estudos posteriores com a extensão dos termos de busca, aos motivos da baixa utilização do uso de marcas pelas empresas, principalmente de produtos fitoterápicos, da identificação de qual tipo de Propriedade Intelectual as empresas consideram mais rentável, assim como ampliar para a busca de proteção de marcas em outros países que poderá mostrar novos caminhos aos brasileiros na gestão de negócios.

\section{Referências}

AAKER, D. A. Managing Brand Equity. Capitalizing on the value of a brand name. Nova Iorque: Free Press, 1991. 39p.

ANVISA - AGÊNCIA NACIONAL DE VIGILÂNCIA SANITÁRIA. Resolução da Diretoria

Colegiada. RDC n. 26, de 13 de maio de 2014. Disponível em: http://bvsms.saude.gov.br/bvs/ saudelegis/anvisa/2014/rdc0026_13_05_2014.pdf. Acesso em: 23 nov. 2020.

ANVISA - AGÊNCIA NACIONAL DE VIGILÂNCIA SANITÁRIA. Formulário Fitoterápico da Farmacopeia Brasileira. [2021]. Disponível em: https:/www.gov.br/anvisa/pt-br/assuntos/ farmacopeia/formulario-fitoterapico. Acesso em: 24 maio 2021.

BATEY, M. O significado da marca: como as marcas ganham vida na mente dos consumidores. Rio de Janeiro: Best Business, 2010.

BRASIL. Lei n. 9.279, 14 de maio de 1996. Regula direitos e obrigações relativos à propriedade intelectual. Diário Oficial [da] República Federativa do Brasil, Poder Executivo, Brasília, DF, 14 de maio de 1996.

BRASIL. Lei n 10.973, de 2 de dezembro de 2004. Dispõe sobre incentivos e à pesquisa científica e tecnológica no ambiente produtivo e dá outras providências. Diário Oficial [da] República Federativa do Brasil, Poder Executivo, Brasília, DF, 2 de dezembro de 2004.

BRASIL. Ministério da Saúde (MS). Política nacional de plantas medicinais e fitoterápicos.

Brasília: Série B. Textos Básicos de Saúde. 2006. Disponível em: http://bvsms.saude.gov.br/bvs/ publicacoes/politica_nacional_fitoterapicos.pdf. Acesso em: 23 nov. 2020.

BUENO, M. J. A.; MARTINEZ, B. B.; BUENO, J. C. Manual de plantas medicinais e

fitoterápicos utilizados na cicatrização de feridas. Porto Alegre: Univás. 2016. 136p.

CASTALDI, C. To trademark or not to trademark: The case of the creative and cultural Industries.

Research Policy, [s.l.], v. 47, p. 606-616, 2018.

CNPJ - CADASTRO NACIONAL DE PESSOA JURÍDICA. Cadastro empresas. [2020]. Disponível em: http://cnpj.info/. Acesso em: 25 nov. 2020.

COSTA, L. S. et al. O complexo produtivo da saúde e sua articulação com o desenvolvimento socioeconômico nacional. Revista do Serviço Público, [s.l.], v. 64, n. 2, p. 177-199, 2013. DOI: https://doi.org/10.21874/rsp.v64i2.120.

DERMAVITA. Informação empresa. [2020]. Disponível em: https://www.dermavita.com.br/. Acesso em: 25 nov. 2020. 
EXTRAFARMA. Fitomelito. [2020]. Disponível em: https://www.extrafarma.com.br/fitomelito-150g/ p\#description. Acesso em: 25 nov. 2020.

FERREIRA, R. L. MIND THE GAP: a Lacuna entre Estratégia e Experiência de Marca. 2018. 148p. Dissertação (Mestrado - Mestrado em Comunicação) - Universidade de Brasília, Brasília, DF, 2018.

FITOBEL. Informação empresa. [2020a]. Disponível em: https://fitobel.negocio.site/. Acesso em: 25 nov. 2020.

FITOBEL. Quem somos. [2020b]. Disponível em: http://fitobel.com.br/quemsomos2.php. Acesso em: 25 nov. 2020.

FLIKKEMA, M. et al. Trademarks' relatedness to product and service innovation: A branding strategy approach. Research Policy, [s.l.], v. 48, n. 6, p. 1.340-1.353, 2019. DOI: https://doi.org/10.1016/j. respol.2019.01.018.

FORMICT - MINISTÉRIO DA CIÊNCIA, TECNOLOGIA, INOVAÇÃO E COMUNICAÇÕES. Formulário para informações sobre a Política de Propriedade Intelectual das Instituições Científicas e Tecnológicas do Brasil. Brasília, DF: Ministério da Ciência, Tecnologia, Inovação e Comunicações, 2019. 64p.

FRANÇA, A.; VASCONCELLOS, G. Patentes de fitoterápicos no brasil: uma análise do andamento dos pedidos no período de 1995-2017. Cadernos de Ciência \& Tecnologia, [s.l.], v. 35, n. 3, p. 329-359, 2018.

HASENCLEVER, L. Diagnóstico dos desafios e oportunidades no mercado de Plantas Medicinais e Fitoterápicos brasileiro: [relatório de pesquisa]. Brasília, DF; Rio de Janeiro: CGEE; UFRJ, 2009.

HASENCLEVER, L. et al. A indústria de fitoterápicos brasileira: desafios e oportunidades. Ciência \& Saúde Coletiva, [s.l.], v. 22, n. 8, p. 2.559-2.569, 2017. DOI: http://dx.doi.org/10.1590/141381232017228.29422016.

HYPERA PHARMA. Informação empresa. [2020]. Disponível em: https://www.hyperapharma.com. br/. Acesso em: 25 nov 2020.

INPI - INSTITUTO NACIONAL DA PROPRIEDADE INDUSTRIAL. Relatório de Atividades INPI. 2018. Disponível em: http://antigo.inpi.gov.br/sobre/estatisticas. Acesso em: 23 nov. 2020

INPI - INSTITUTO NACIONAL DA PROPRIEDADE INDUSTRIAL. Marcas. 2020a. Disponível em: https:/www.gov.br/inpi/pt-br/servicos/perguntas-frequentes/marcas\#marca. Acesso em: 23 nov. 2020.

INPI - INSTITUTO NACIONAL DA PROPRIEDADE INDUSTRIAL. Classificação de Produtos e Serviços. 2020b. Disponível em:https://www.gov.br/inpi/pt-br/servicos/marcas/classificacao-marcas. Acesso em: 23 nov. 2020.

INTERBRAND. Ranking Best Global Brands. 2020. Disponível em: https://www.interbrand.com/ best-brands/. Acesso em: 23 maio 2021.

KELLER, K.; MACHADO, M. Gestão estratégica de marcas; São Paulo: Pearson Prentice Hall, 2006.

MAZUCATO, T. et al. Metodologia da pesquisa e do trabalho científico. Penápolis: FUNEPE, 2018. $96 \mathrm{p}$. 
MEDEIROS FILHO, A. R. de; RUSSO, S. L. Gestão de registro de marcas em empresas sergipanas: da abertura da empresa até o pedido de registro. Revista Geintec, [s.l.], v. 5, n. 4, p. 2.640-2.651, 2015. DOI: http://dx.doi.org/10.7198/s2237-0722201500040014.

MINISTÉRIO DA SAÚDE. Ações e Programas. Programa Nacional de Plantas Medicinais e Fitoterápicos. [2021]. Disponível em: https://antigo.saude.gov.br/acoes-e-programas/programanacional-de-plantas-medicinais-e-fitoterapicos-ppnpmf?view=default. Acesso em: 24 maio 2021.

PEREIRA, T. S. Os registros de marcas no Brasil: uma proposta de um guia prático para facilitar o depósito no INPI. 2018. 41p. Dissertação (Mestrado Profissional em Propriedade Intelectual e Transferência de Tecnologia para a Inovação) - Universidade de Brasília, Brasília, DF, 2018.

PINHO, J. B. O poder das marcas. São Paulo: Summus, 1996.

RICARDO, R. Pesquisa incentiva cultivo de plantas medicinais em Vargem Grande. Rio de Janeiro: Faperj, 2009. Disponível em: http://www.faperj.br/?id=1516.2.3. Acesso em: 23 maio 2021.

SEBRAE - SERVIÇO BRASILEIRO DE APOIO ÀS MICRO E PEQUENAS EMPRESAS.

Importância da marca para sucesso do negócio. 2020. Disponível em: https:/www.sebrae.com. br/sites/PortalSebrae/artigos/importancia-da-marca-para-sucesso-do-negocio,48f9634e2ca62410Vgn VCM100000b272010aRCRD. Acesso em: 24 nov. 2020.

SEVERINO, A. J. Metodologia do trabalho científico. 2. ed. São Paulo: Cortez, 2017.

TAVARES, L. D. Diretrizes para gestão de marca (“branding”) em organizações brasileiras: resultado de pesquisa de opinião com especialistas. 2016. 88p. Dissertação (Mestrado em Sistemas de Gestão) - Universidade Federal Fluminense, Niterói, RJ, 2016.

TERRA JUNIOR, O. N.; MALDONADO, J. V.; ARNOBIO, A. Estudo do Desempenho Comercial dos Insumos Farmacêuticos Vegetais sob a Ótica do Comércio Exterior. Revista Fitos, [s.l.], v. 9, n. 3, p. 233-246, 2015. Disponível em: https://revistafitos.far.fiocruz.br/index.php/revista-fitos/article/ view/252. Acesso em: 25 maio 2021.

TORRES, K. R. Os arranjos produtivos locais (APLs) no contexto da implementação da Política e do Programa Nacional de Plantas Medicinais e Fitoterápicos. 2013. 143p. Dissertação (Mestrado em Profissional em Saúde Pública) - Escola Nacional de Saúde Pública Sergio Arouca, Rio de Janeiro, 2013.

\section{Sobre os Autores}

\section{Daniel Marques de Albuquerque}

E-mail: danielmalb@gmail.com ORCID: https://orcid.org/0000-0001-7747-0543

Mestrando em Propriedade Intelectual e Transferência de Tecnologia para Inovação pelo PROFNIT em 2021. Endereço profissional: Av. General Rodrigo Octavio Jordão Ramos, n. 1.200, Coroado I, Manaus, AM. CEP: 69067-005. 


\section{Sammy Aquino Pereira}

E-mail: sammy.aquino@gmail.com

ORCID: https://orcid.org/0000-0002-2535-4783

Doutora em Agronomia Tropical pela Universidade Federal do Amazonas em 2015.

Endereço profissional: Av. André Araújo, n. 2.936, Petrópolis, Manaus, AM. CEP: 69067-375. 